\title{
Development of Pressure Swing Adsorption Technology for Spacesuit Carbon Dioxide and Humidity Removal
}

\author{
William Papale \\ Hamilton Sundstrand \\ Heather Paul, Gretchen Thomas \\ NASA Johnson Space Center
}

Copyright $\odot 2006$ SAE International

\begin{abstract}
Metabolically produced carbon dioxide $\left(\mathrm{CO}_{2}\right)$ removal in spacesuit applications has traditionally been accomplished utilizing non-regenerative Lithium Hydroxide (LiOH) canisters. In recent years, regenerative Metal Oxide (MetOx) has been developed to replace the Extravehicular Mobility Unity (EMU) LiOH canister for extravehicular activity (EVA) missions in micro-gravity, however, MetOx may carry a significant weight burden for potential use in future Lunar or planetary EVA exploration missions. Additionally, both of these methods of $\mathrm{CO}_{2}$ removal have a finite capacity sized for the particular mission profile. Metabolically produced water vapor removal in spacesuits has historically been accomplished by a condensing heat exchanger within the ventilation process loop of the suit life support system.
\end{abstract}

Advancements in solid amine technology employed in a pressure swing adsorption system have led to the possibility of combining both the $\mathrm{CO}_{2}$ and humidity control requirements into a single, lightweight device. Because the pressure swing adsorption system is regenerated to space vacuum or by an inert purge stream, the duration of an EVA mission may be extended significantly over currently employed technologies, while markedly reducing the overall subsystem weight compared to the combined weight of the condensing heat exchanger and current regenerative $\mathrm{CO}_{2}$ removal technology. This paper will provide and overview of ongoing development efforts evaluating the subsystem size required to manage anticipated metabolic $\mathrm{CO}_{2}$ and water vapor generation rates in a spacesuit environment.

\section{INTRODUCTION}

The two current technologies employed for carbon dioxide $\left(\mathrm{CO}_{2}\right)$ control in the Extravehicular Mobility Unit (EMU) include non-regenerative Lithium Hydroxide $(\mathrm{LiOH})$ and regenerative Metal Oxide (MetOx) sorbent canisters. Each of these technologies utilize chemical sorbents to remove the metabolically produced $\mathrm{CO}_{2}$ from the internal ventilation loop of the spacesuit, maintaining a safe, breathable atmosphere. The mass of chemical required for each canister is based on maintaining the inhaled $\mathrm{CO}_{2}$ partial pressure $\left(\mathrm{ppCO}_{2}\right)$ below the required limits for the duration of one Extravehicular Activity (EVA) over a range of anticipated metabolic loads. Each of these technologies has a finite capacity for $\mathrm{CO}_{2}$ based on the total sorbent mass loaded into the canister, and along with the oxygen supply and battery capacity, must be considered when specifying a desired EVA duration. For the case of the MetOx sorbent technology, the canisters are regenerated on the International Space Station (ISS) following an EVA and may be subsequently re-used; however, LiOH canisters are considered expendable and may be used only once before requiring a recharge at a ground based facility.

While on EVA, humidity control in the current EMU ventilation loop is accomplished by a condensing heat exchanger. The heat sink for condensing the water vapor is provided by the latent heat of sublimation of stored liquid water to space vacuum on the adjacent side of the ventilation loop condensing heat exchanger. Controlling the humidity in the suit atmosphere is important primarily to prevent visor fogging and improve the overall thermal comfort within the suit. The condensed liquid water is separated from the ventilation gas stream by means of a mechanical rotary separator and stored for eventual use as feed for the sublimation portion of the process.

Future exploration missions to Lunar and planetary surfaces will benefit from technologies that allow for greater EVA duration without incurring additional weight penalties associated with increased $\mathrm{CO}_{2}$ sorbent mass, additional expendables or vehicle systems required for sorbent regeneration. Additionally, a continuous process by which both the $\mathrm{CO}_{2}$ and humidity control is incorporated into a single subsystem is beneficial in simplifying the ventilation loop process requirements and improving overall system reliability. Recent 
advancements in solid amine sorbent technology have demonstrated both the capacity and reactivity to concurrently adsorb water vapor and $\mathrm{CO}_{2}$ when employed in a pressure swing adsorption system. Coupled with a proprietary Hamilton Sundstrand solid amine sorbent, prototype hardware developed during past activities has been utilized to investigate the lightest weight system attainable while meeting the requisite metabolic performance requirements in a spacesuit environment. This paper will provide an overview of the progress in developing a solid amine-based pressure swing adsorption system for combined $\mathrm{CO}_{2}$ and humidity control in advanced EMU applications.

\section{OVERVIEW OF SYSTEM DEVELOPMENT}

The solid amine pressure swing adsorption system functions on a semi-continuous basis by operating between two adjacent sorbent beds. While one bed is exposed to the ventilation loop flow removing $\mathrm{CO}_{2}$ and water vapor, the other is regenerated by means of vacuum exposure or inert sweep gas. Once the capacity limit is reached on the adsorbing bed, the vent loop flow is diverted to the regenerated sorbent bed while the exhausted bed is exposed to vacuum or inert purge gas for regeneration. A novel spool valve is used to simultaneously divert the vent loop flow direction while also isolating and exposing the exhausted bed to the regeneration flow path. Figure 1 illustrates the modes of operation for a two-bed system using external vacuum as the regeneration path.
An important aspect of the solid amine adsorption system is the transfer of heat between the adsorbing and regenerating sorbent beds. The chemical adsorption of $\mathrm{CO}_{2}$ and water vapor by the solid amine results in an exothermic heat of reaction, which, if not adequately rejected, adversely affects the capacity and reaction kinetics of the sorbent. Alternately, the reverse reaction of regeneration absorbs heat from the surroundings. Without sufficient heat input, the effectiveness of the regeneration period is reduced, which in turn affects the cyclic capacity and overall reaction kinetics of the subsequent adsorption period. A simple and low power means of integrated heat rejection and absorption is accomplished by providing an adequate conductive heat transfer path between the two sorbent beds.

Development efforts in 1996-1997, and outlined in Reference 1, demonstrated a solid amine based pressure swing adsorption system utilizing a development sorbent named HSX. The canister design for this activity was designed based on HSX chemical performance and allowed for a block canister design, shown in Figure 2, which simplified the canister manufacture compared to alternative designs. Subsequent to this development activity, a new Hamilton Sundstrand solid amine formulation resulted in a near $25 \%$ increase in $\mathrm{CO}_{2}$ capacity with improved reaction kinetics and life characteristics over HSX. The new sorbent, named SA9T, was incorporated into the canister and spool valve assembly developed previously.

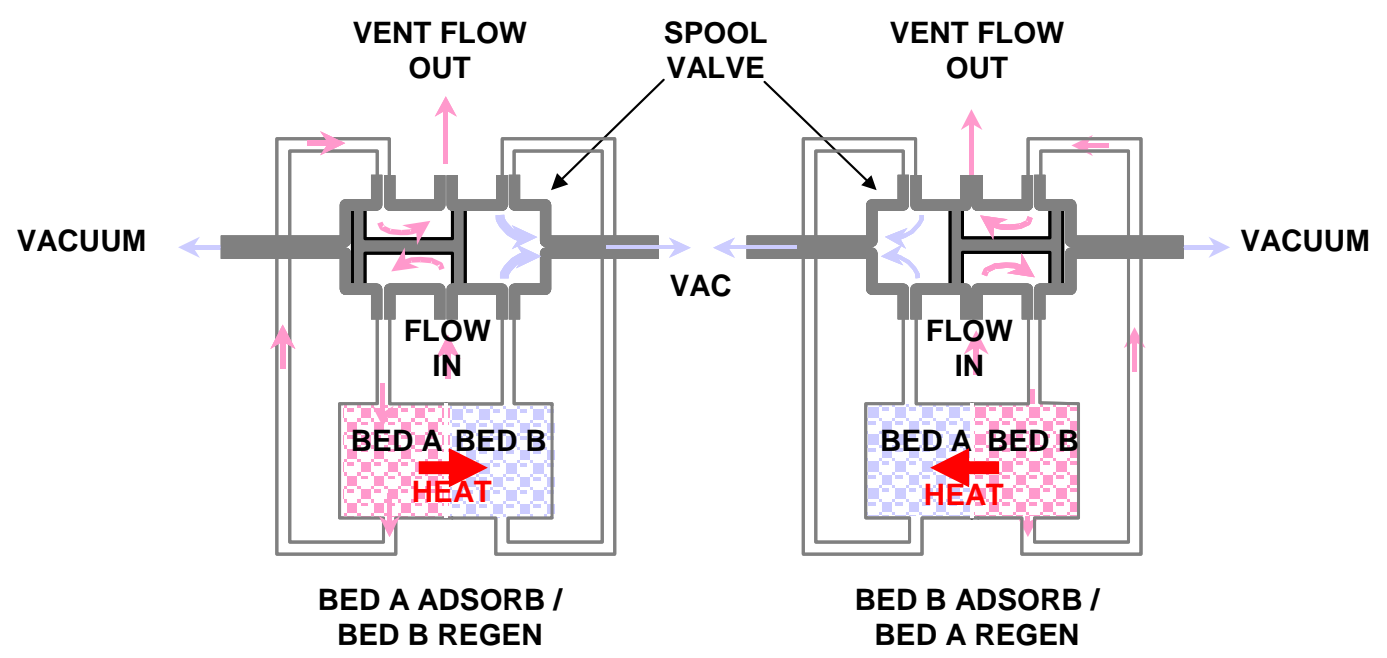

Figure 1: Simplified Flow Schematic of Solid Amine-Based, Pressure Swing Adsorption System 


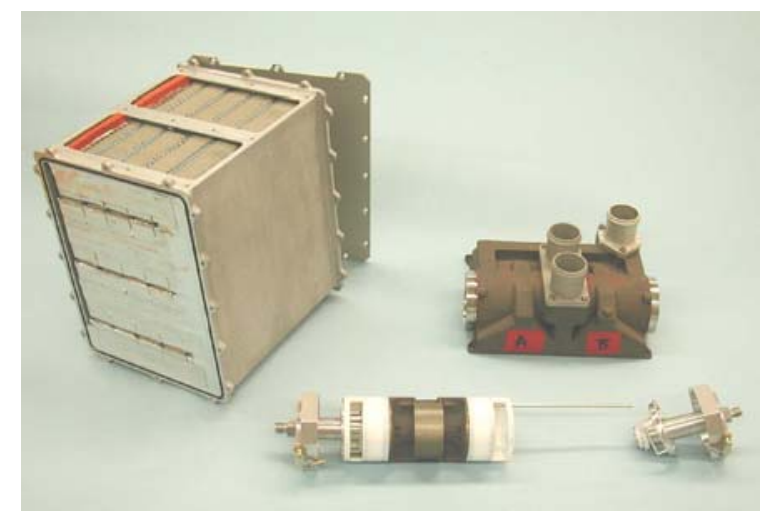

Figure 2: Block Canister Design and Pneumatically Operated Spool Valve

\section{PERFORMANCE TESTING AND ANALYSIS}

Performance testing with SA9T sorbent loaded in the block canister design demonstrated lower cyclic capacity and adsorption kinetics compared to a canister with higher conductive heat transfer capability between the sorbent beds. Data from internal bed thermocouples, provided in Figure 3, demonstrate the resulting cyclic sorbent bed temperature profiles for the block canister design. In comparison, the resulting temperature profile for a canister with good heat transfer between the sorbent beds and tested under similar conditions demonstrates nearly isothermal performance between the adsorption and regeneration periods. The observed temperature swing for the block canister design can be attributed to near adiabatic performance. During the adsorption period, heat is liberated as $\mathrm{CO}_{2}$ and water vapor react with the solid amine. As the bed temperature increases, the capacity and rate for adsorbing $\mathrm{CO}_{2}$ and water vapor decrease compared to an isothermal case. Conversely, when the solid amine is exposed to vacuum, heat is absorbed as $\mathrm{CO}_{2}$ and water vapor are removed from the sorbent. The consequent reduction in temperature during the regeneration period diminishes the rate at which $\mathrm{CO}_{2}$ and water vapor can be removed from the sorbent, resulting in a reduced regeneration compared to an isothermal case.

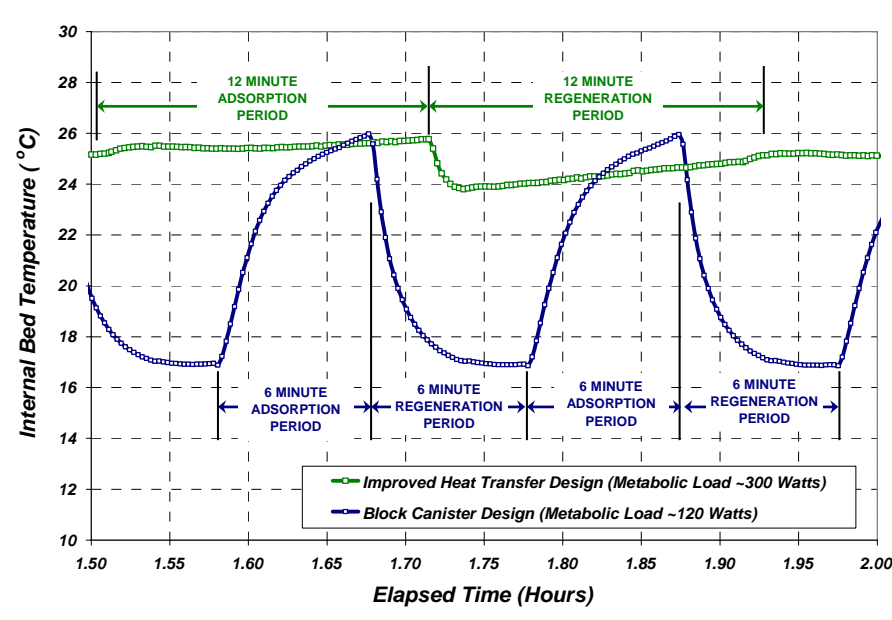

Figure 3: Thermal Performance Comparison of Block Canister Design and Improved Heat Transfer Design

An alternative canister concept with improved heat transfer characteristics and based on the EMU Metal Oxide canister geometric envelope was subsequently designed and manufactured. Figure 4 provides a photograph comparison between an EMU Metal Oxide canister and the improved solid amine development canister. The SA9T sorbent was unloaded from the block canister and loaded into the new design. To further accelerate system performance evaluations, the new solid amine canister was coupled with the pneumatically actuated spool valve that was originally developed for the block canister design by means of a plastic flow distributor, as illustrated in Figure 5.

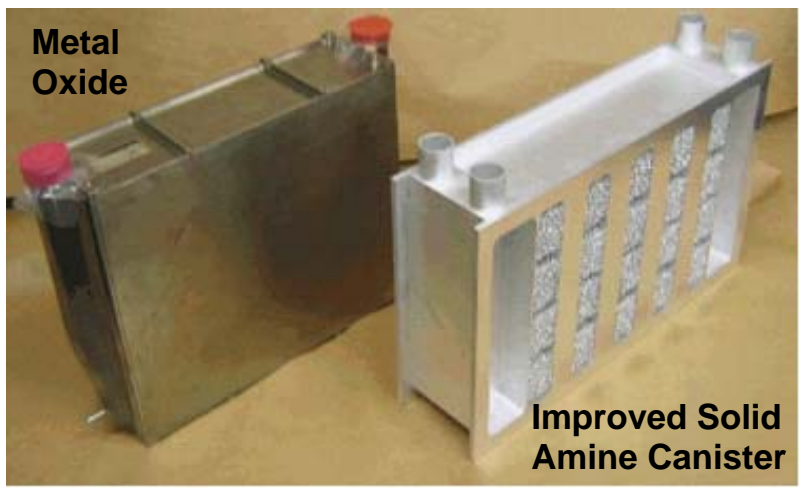


Figure 4: Relative Size of Improved Solid Amine Canister

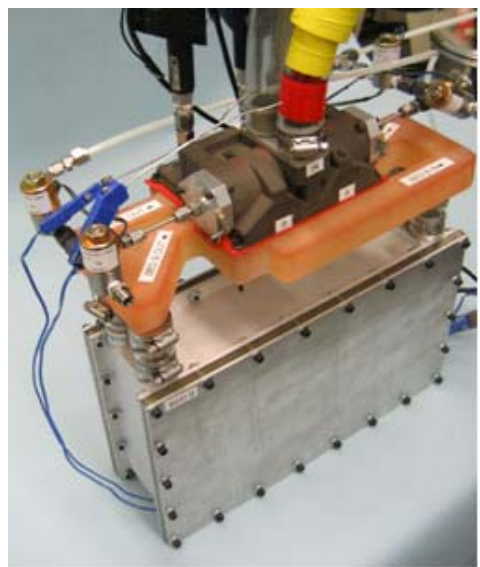

Figure 5: Improved Solid Amine Canister with Pneumatically Operated Spool Valve 
The nominal closed loop $\mathrm{CO}_{2}$ adsorption profile for each solid amine canister design is observed in Figure 6, which corresponds to the temperature profile for each respective adsorption period in Figure 3 . Process air flow was set at 6 ACFM (170 ALPM) while the $\mathrm{CO}_{2}$ injection rate was set for a specific metabolic generation rate, not to exceed $7.6 \mathrm{mmHg} \mathrm{ppCO}$ at the outlet of the system. Note that significantly enhanced $\mathrm{CO}_{2}$ adsorption performance is observed for the improved canister design, which demonstrated the ability to remove an equivalent 300 Watt $(1023 \mathrm{Btu} / \mathrm{hr}) \quad \mathrm{CO}_{2}$ metabolic load compared to a 120 Watt (409 Btu/hr) metabolic load for the block canister design.

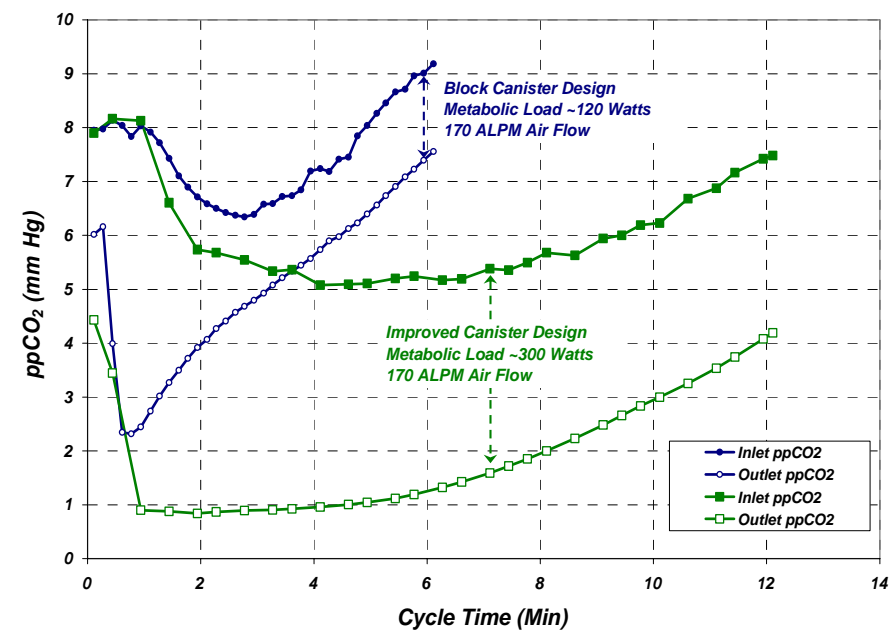

Figure 6: Closed Loop $\mathrm{CO}_{2}$ Removal Performance of Block Canister and Improved Solid Amine Canister

Water vapor removal performance for the improved canister design over a range of inlet air humidity and flow rates demonstrates a near linear relationship as illustrated in Figure 7.

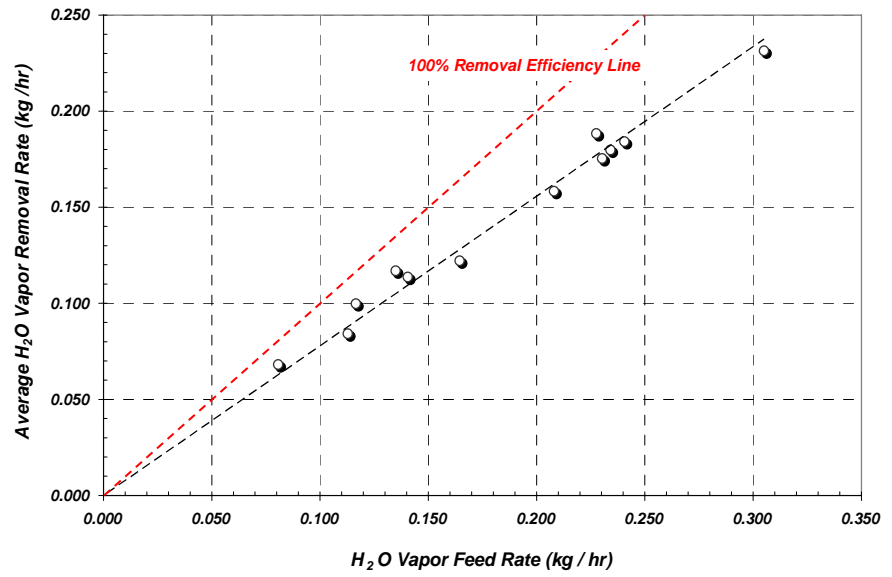

Figure 7: Observed Water Vapor Removal Performance for SA9T in Improved Solid Amine Canister

To meet a nominal water vapor removal rate requirement of $0.14 \mathrm{~kg} / \mathrm{hr}$ at a 300 Watt metabolic load (2), the data suggests that a water vapor feed rate of
$0.18 \mathrm{~kg} / \mathrm{hr}$ is required to the inlet of the system. Based on an a suit ventilation flow rate of 170 ALPM, this influent water vapor mass flow rate corresponds to a water vapor partial pressure of $14.16 \mathrm{~mm} \mathrm{Hg}$, or dew point of approximately $16.6^{\circ} \mathrm{C}\left(61.9^{\circ} \mathrm{F}\right)$. This value is consistent with current EMU models for the air stream entering the $\mathrm{LiOH}$ cartridge at equivalent metabolic loads.

\section{FUTURE WORK}

Using the improved canister design and pneumatic spool valve test assembly, parametric studies were performed to investigate further reductions in sorbent bed size and weight. For advanced EMU applications that are intended for Lunar and planetary surface exploration, aggressive targets have been established to reduce the overall life support system (LSS) on-back weight. The goal for this system is to achieve a weight of $4 \mathrm{~kg}$ while still meeting the current EMU metabolic $\mathrm{CO}_{2}$ and water vapor removal requirements. To achieve this system weight, a significant reduction in sorbent and canister weight is necessary.

The reduction in sorbent weight and volume reduces the cyclic $\mathrm{CO}_{2}$ and water vapor capacity, and will therefore result in shorter adsorption and regeneration periods compared to the current canister design, however, EVA duration will not be affected by this reduction in overall system weight since the process is continuously regenerated to vacuum. As a comparison, reduction in Metal Oxide or $\mathrm{LiOH}$ canister sorbent weight would have a direct impact on allowable EVA duration based on the corresponding reduction in $\mathrm{CO}_{2}$ removal capacity. Furthermore, by providing an advanced, active feedback control scheme, by which the breathing air returning to the helmet is monitored for $\mathrm{ppCO}_{2}$ and dew point, will allow the solid amine pressure swing adsorption system to optimize the cycle time for the applied metabolic load. So long as the sorbent mass and cycle time are designed for the worst case metabolic rate conditions, the system will provide more than adequate performance for nominal conditions.

Design and manufacture of a reduced size system that will investigate a variable cycle time are ongoing. Additional performance evaluations are planned and necessary to evaluate the overall system impact of sorbent-based humidity control for spacesuit applications and to further the operating database for combined $\mathrm{CO}_{2}$ and humidity control.

\section{SUMMARY}

Evaluations of a solid amine sorbent in two canister design configurations have demonstrated the importance in providing sufficient heat transfer rates to and from the sorbent bed during adsorption and vacuum regeneration operations. Prototype system performance evaluations have demonstrated the ability to concurrently remove $\mathrm{CO}_{2}$ and water vapor at the necessary rates to meet EVA metabolic rate challenges. 
Since the system operates on a semi-continuous basis when vacuum is available for regeneration, significant enhancements to EVA systems are possible, including longer EVA duration, reduced expendables for $\mathrm{CO}_{2}$ removal, and reduced system maintenance requirements. Further system weight reductions are possible and are under investigation.

\section{REFERENCES}

1. Filburn, T., Dean, W.C., and Thomas, G., "Development of a Pressure Swing $\mathrm{CO}_{2} / \mathrm{H}_{2} \mathrm{O}$ Removal System for an Advanced Sapcesuit," SAE Paper No. 981673, 1998.

2. NASA Publication RP-1324, "Designing for the Human Presence in Space: An Introduction to Environmental Control and Life Support Systems," 1994.

\section{CONTACT INFORMATION}

William Papale

Hamilton Sundstrand

william.papale@hs.utc.com 